\title{
Performance of urinary survivin as a non-invasive molecular marker of bladder carcinoma in a schistosomiasis endemic area
}

\author{
Abubakar S. Muhammad ${ }^{1}$, Ismaila A. Mungadi ${ }^{1}$, Enemeka D. Ndodu² and Garba D. Kalayi ${ }^{3}$ \\ Ghana Med J 2018; 52(2): 74-78 doi: http://dx.doi.org/10.4314/gmj.v52i2.2 \\ ${ }^{1}$ Urology Unit, Department of Surgery, Usmanu Danfodiyo University Teaching Hospital, Sokoto, Nigeria, ${ }^{2}$
Centre for Advanced Medical Research and Training, Usmanu Danfodiyo University Sokoto, Nigeria, ${ }^{3}$ Urol-
ogy Division, Department of Surgery, Ahmadu Bello University Teaching Hospital Zaria, Nigeria.
}

Corresponding author: Abubakar Sadiq Muhammad

Conflict of interest: None declared

E-mail:asmgusau@gmail.com

\section{SUMMARY}

Objective: To compare the sensitivity, specificity, positive predictive value, negative predictive value of urinary survivin and that of urine cytology in the diagnosis of bladder carcinoma in a schistosoma endemic area.

Design and setting: This is a 12-month prospective study of patients with features of bladder carcinoma as study group and patients with other urologic conditions and healthy volunteers as control group.

Participants: Patients with features of bladder carcinoma formed the study group, while patients with other urological conditions and healthy volunteers formed the control group.

Results: There were 52 patients in study group and 36 patients in control group. The mean ages of patients in the study and control groups were $47.17 \pm 17.00$ and $44.19 \pm 18.89$ years respectively. There were 48 males and 4 females in the study group, giving a male: female ratio of $12: 1$. Thirty-one $(60 \%)$ of the patients were farmers and 44 patients $(85 \%)$ had history suggestive of schistosomiasis at childhood. The sensitivity of urine cytology and survivin in the study were $29.1 \%$ and $100.0 \%$ respectively. The specificity of urine cytology and survivin were $100.0 \%$ and $100.0 \%$ respectively $(\mathrm{p}=0.05)$. The marker was associated with false positive $(\mathrm{FP})$ results in patients with prostate cancer.

Conclusion: Urinary survivin is highly sensitive, specific and predictive of bladder carcinoma in our environment. The marker is associated with false positive results in patients with prostate cancer.

Funding: By authors

Keywords: survivin, urinary bladder carcinoma, schistosomiasis, sensitivity, specificity

\section{INTRODUCTION}

Bladder cancer is the ninth most common cancer and $13^{\text {th }}$ most common cause of death worldwide. ${ }^{1}$ In Sokoto North-Western (NW) Nigeria, bladder cancer is the commonest male malignancy and sixth most common malignancy in women. ${ }^{2}$ In the western world, transitional cell carcinoma accounted for $95-97 \%$ of bladder cancer. ${ }^{3}$ In Africa transitional cell carcinoma and squamous cell carcinoma of bladder accounted for $60-90 \%$ and $10-40 \%$ of cases respectively. ${ }^{3}$ In Sokoto, Nigeria, squamous cell carcinoma and transitional cell carcinoma accounted for $65.1 \%$ and $27.9 \%$ of bladder cancer due to endemicity of schistosomiasis. ${ }^{4}$ Most of the patients present with advanced disease at diagnosis which was also noticed in other African countries where schistosomiasis is endemic. ${ }^{5}$ The main stay for screening, diagnosis and surveillance of patients with bladder carcinoma are urine cytology and cystoscopy with or without biopsy.
Urine cytology although specific, is poorly sensitive for low grade tumours and dependent on the experience of pathologist. ${ }^{6}$ Cystoscopy with biopsy is the gold standard method for bladder cancer diagnosis but is invasive, costly and cannot reliably identified small or flat lesions (carcinoma in situ) without use of an adjunct such as cytology, narrow band imaging and blue light cystoscopy. ${ }^{6,7}$ There is, therefore, need for simple, noninvasive, and effective tool for screening, diagnosis and follow-up of patients after treatment. Urinary molecular markers are currently being investigated and produced encouraging results. ${ }^{8}$ Survivin is a multifunctional protein that has been demonstrated to inhibit apoptosis, regulate cell division and promote angiogenesis by binding to and inactivating second mitochondriaderived activator of caspases (SMAC). ${ }^{9,10}$ 
The objective of the study was to compare the sensitivity, specificity, positive predictive value, negative predictive value of urinary survivin and that of urine cytology in diagnosis of bladder carcinoma in schistosomiasis endemic area.

\section{METHODS}

This is a prospective study carried out within 12 months (January- December, 2014) at our hospital. The study was approved by Health Research and Ethics Committee of Usmanu Danfodiyo University Teaching Hospital (UDUTH), Sokoto with a reference number of UDUTH/HERC/2012/No.38. Only patients that gave informed consent were recruited for the study.

Consecutive patients with features of bladder cancer who presented at urology outpatient or Accident and Emergency departments of Usmanu Danfodiyo University Teaching Hospital and met the inclusion criteria were recruited as study group. Patients with other urologic conditions and healthy volunteers formed the control group. Haematuria is defined as presence of $\geq 3$ red blood cells/ high power field of urine specimen.

The inclusion criteria included: confirmed cases of bladder cancer before the study, clinical or radiological bladder mass, haematuria in patients with significant history schistosomiasis and or smoking. The exclusion criteria included patients who had previous treatment for bladder cancer such as radical cystectomy, chemotherapy and patients that refused consent.

\section{Urine sample collection and processing}

Freshly voided urine or babotage sample of $50 \mathrm{ml}$ was collected and divided in to 2 for urine cytology and survivin assay. For urine cytology, the sample was promptly fixed in 50\% alcohol within 1 hour of collection and centrifuged at $2000 \mathrm{rpm}$ for 5-10 minutes. The sediment was smeared on albuminised slides, stained with Papanicolaou stain and examined under microscope. ${ }^{12}$ Atypical, suspicious and malignant results were considered positive for the presence of cancer. For survivin assay the sample was immediately frozen at $-200 \mathrm{C}$ till the time of the assay when the samples were brought to room temperature. ${ }^{13}$

\section{Urethrocystoscopy and bimanual palpation}

Urethrocystoscopy, biopsy of the suspicious lesion and bimanual palpation under general anaesthesia was done to stage the tumour. The samples were sent for histology in $10 \%$ formalin.

\section{Histology}

The biopsy samples were grossed, processed and embedded in wax. The tissues were cut in to $5 \mathrm{~mm}$ sections and stained with Haematoxylin and Eosin stains. Slides were prepared and examined under microscope for tissue diagnosis, grade and invasion. ${ }^{14}$

\section{Survivin Assay Using Elisa Method}

Two (2) ml urine samples were centrifuged at $1000 \mathrm{rpm}$ for 1 minute. The reagents, urine samples and Survivin standards were prepared according to the manufacturer's instruction. Standard wells were prepared from 1-8 by adding $300 \mu \mathrm{L}$ of human survivin in the first well and diluents in the other 7 wells. The human survivin was serially diluted in the 7 wells containing the diluents, with the $8^{\text {th }}$ well achieving zero concentration of the human survivin serving as negative control. Urine of $100 \mu \mathrm{L}$ was added into the remaining 88 wells which were coated with human anti survivin monoclonal antibody.

The plate containing the wells was covered with paper foil and incubated at $37{ }^{\circ} \mathrm{C}$ for 90 minutes. The plate was washed using automated plate washer for 3 minutes at $500 \mathrm{rpm}$. The wells were emptied of the remaining wash solution. Biotinylated polyclonal survivin antibody $(100 \mu \mathrm{L})$ was added to each well, covered with paper foil and incubated at $37^{\circ} \mathrm{C}$ at $500 \mathrm{rpm}$ for 1 hour. The wells were washed 3 times using automated washer and emptied of the remaining wash solution. ${ }^{15}$

The enzyme-conjugate solution $(100 \mu \mathrm{L})$ was added to each well, covered with paper foil and incubated at 500 $\mathrm{rpm}$ at $37{ }^{\circ} \mathrm{C}$ for 30 minutes. The wells were washed 5 times and subsequently emptied. Substrate solution (100 $\mu \mathrm{L}$ ) was added to each well and incubated for 30 minutes. Hundred (100) $\mu \mathrm{L}$ of mixture of colour reagent $\mathrm{A}+\mathrm{B}$ was added to each well and hatched in dark incubator at $37{ }^{\circ} \mathrm{C}$. One hundred (100) $\mu \mathrm{L}$ of colour reagent $\mathrm{C}$ was added to each well and mixed very well. Optical density (OD) was read at $450 \mathrm{~nm}$ within 10 minutes. $^{15}$

\section{Data collection}

Relevant data was collected through a semi-structured proforma which included clinical features and risk factors for bladder carcinoma, results of relevant investigations, cystoscopy findings, and results of histology, urine cytology, and Survivin assay.

\section{Data analysis}

Data analysis was done using Statistical Package for Social Sciences 20.0 version (2011) for windows (IBM, SPSS Inc., Chicago, IL, USA). Categorical data between the study group and control subgroups were compared by chi square and quantitative data were compared by non-parametric tests. Comparisons of the age groups (study and control groups) and urinary markers were done using ANOVA. 
Receiver operating characteristic (ROC) curve used to calculate optimal cut off value for survivin with the highest sensitivity and specificity. The level of significance was set as $\mathrm{p}<0.05$ at $95 \%$ confidence interval (95\% CI).

\section{RESULTS}

A total number of 88 patients participated in the study with 52 in the study group (SG) and 36 in control group (CG). The socio-demographic characteristics of the patients are shown table 1 below.

Table 1Socio-demographic characteristics of the atients

\begin{tabular}{|c|c|c|c|}
\hline Parameter & $\begin{array}{l}\text { Study Group } \\
\mathbf{n}=52\end{array}$ & $\begin{array}{l}\text { Control } \\
\text { group } \\
\text { n=36 }\end{array}$ & p value \\
\hline Mean age + SD & $47.0 \pm 17.0$ & $44.0 \pm 19.0$ & $0.412^{*}$ \\
\hline Sex & & & \\
\hline Male & 48 & 36 & \\
\hline Female & 4 & 0 & $0.061^{* *}$ \\
\hline Occupation & & & \\
\hline Farmers & $31(59.6)$ & $20(55.5 \%)$ & \\
\hline Civil servants & $9(17.3 \%)$ & $12(33.3 \%)$ & $0.186^{*}$ \\
\hline Students & $3(5.8 \%)$ & $2(5.62 .7 \%)$ & \\
\hline Others & $9(17.3 \%)$ & $2(5.6 \%)$ & \\
\hline Total & 52 & 36 & \\
\hline
\end{tabular}

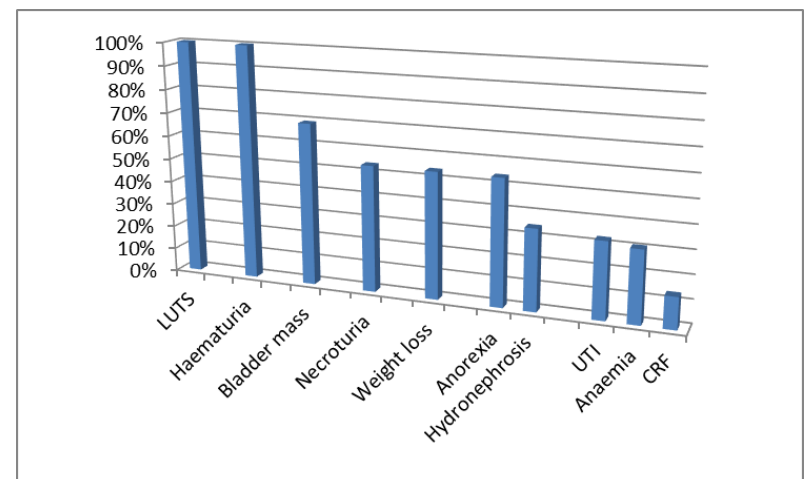

LUTS- lower urinary tract symptoms, UTI- urinary tract infection, CRF- chronic renal failure

Figure 1 Mode of Presentation of Patients in the Study group $(\mathrm{n}=52)$.

The presentations of the patients were shown in Figure 1. There was history suggestive of schistosomiasis in 44 patients $(85.0 \%)$, while 4 patients $(7.7 \%)$ smoked cigarette.

At cystoscopy, 7 patients (13.5\%) had features suggestive of chronic schistosomiasis, 5 patients $(9.6 \%)$ had features of cystitis, 2 patients $(3.8 \%)$ had features of early bladder carcinoma and 38 patients $(73.1 \%)$ had features of advanced bladder carcinoma. The features of chronic schistosomiasis were sandy patches, tubercles and nodules.
The early bladder carcinoma appeared as red patches, papilloma, papillary or sessile solitary lesions less than $2 \mathrm{~cm}$. The advanced carcinoma appeared as huge exophytic bladder masses occupying most or part of the bladder. There were extensive necroturia and ulceration of some of the masses.

Urinary survivin was more sensitive and equaly specific as urine cytology. The comparison of the sensitivity, specificity and predictive values of the markers are shown in table 2 below.

Table 2 Comparison of sensitivity, specificity and predictive values of Survivin and urine cytology

\begin{tabular}{|l|l|l|l|l|}
\hline $\begin{array}{l}\text { Urine } \\
\text { test }\end{array}$ & Sensitivity & Specificity & PPV & NPV \\
& & & & \\
\hline Survivin & $100.0 \%$ & $100.0 \%$ & $80.2 \%$ & $80.0 \%$ \\
Cytology & $29.1 \%$ & $100.0 \%$ & $96.2 \%$ & $25.6 \%$ \\
\hline
\end{tabular}

Using receiver operating characteristic (ROC) curve survivin had good and better area under the curve (AUC) of 0.72 when compared to 0.38 of urine cytology (Figure 2) and the difference was statistically significant, $p=0.015$. Figure 3 below is the ROC curve of survivin and urine cytology. Using the curve the optimal cut off value for Survivin of $18.81 \mathrm{pg} / \mathrm{ml}$ produced sensitivity and specificity of $100.0 \%$ and $100.0 \%$ respectively.

The most common histopathological type of bladder carcinoma was SCC, this was found in 25 patients $(59.5 \%)$ while TCC and adenocarcinoma were found in 16 patients $(38.1 \%)$ and 1 patient $(2.4 \%)$ respectively. There was histological finding of schistosoma ova in the biopsy samples of 18 patients $(46.6 \%)$. Two patients in the study group have premalignant lesions, in form of squamous metaplasia with cystitis cystica and a papilloma.

The mean concentration of urinary markers correlated positively with grade but negatively with stage of bladder carcinoma, $(p=0.001)$. The mean concentrations of the survivin in patients with SCC and adenocarcinoma were significantly higher than that of TCC, $\mathrm{p}=0.001$.

Urine survivin at cut off value of $18.81 \mathrm{pg} / \mathrm{ml} 100.0 \%$ specific in patients with benign urologic conditions (stricture, stone, benign prostatic hyperplasia) and healthy volunteer but false positive in prostate cancer patients. 
In sub-group analysis of mean survivin concentration, the lowest values were recorded in the healthy volunteers and those with benign urological conditions, $\mathrm{p}=0.001$. The mean concentrations of the survivin in the various groups and subgroups are shown in Table 3.

\section{ROC Curve}

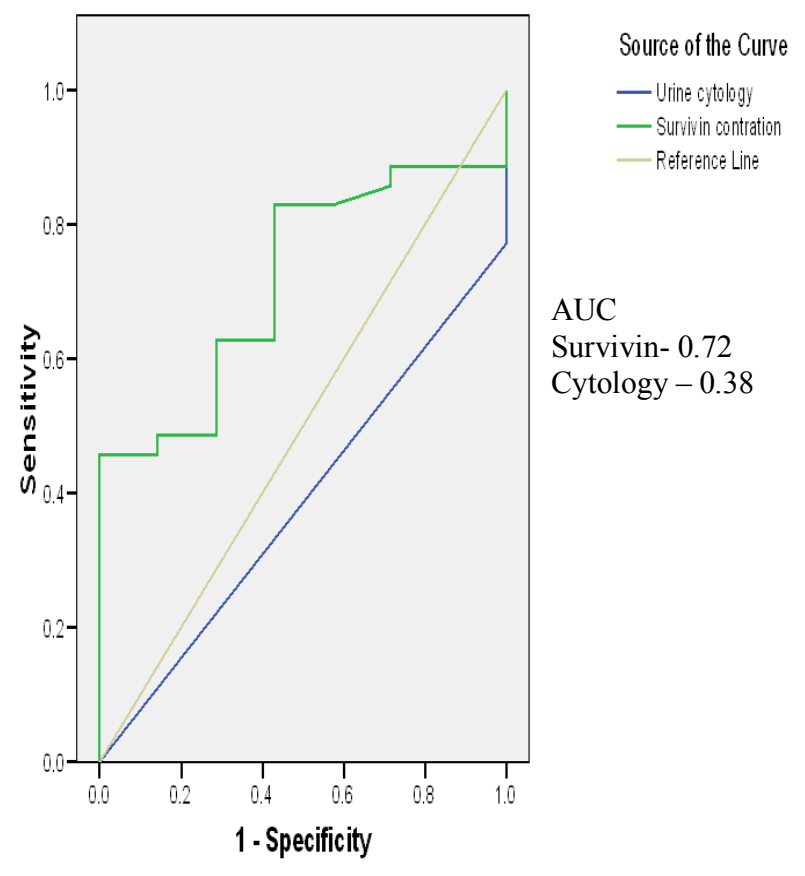

Diagonal segments are produced by ties.

Figure 2 ROC curve for Survivin ELISA and Urine cytology

Table 3 Comparison of Mean values of Survivin among SG and CG

\begin{tabular}{|l|l|l|l|}
\hline $\begin{array}{l}\text { Urinary } \\
\text { marker }\end{array}$ & Group & Mean value \pm SD & p value \\
\hline & SG & $243.01 \pm 374.5$ & $0.0001^{* *}$ \\
& CG & $187.88 \pm 558.71$ & \\
Survivin & $\begin{array}{l}\text { Benign diseases } \\
\text { (stricture, stone, }\end{array}$ & $4.46 \pm 0.00$ & \\
& BPH) & $280.04 \pm 739.51$ & $0.0001^{*}$ \\
& CAP & $17.42 \pm 14.9$ & \\
\hline HV & \\
\hline
\end{tabular}

Key: $:^{*}=$ Kruskal- Wallis test, ${ }^{* *}=$ Friedman's test, $\mathrm{BPH}=$ benign prostatic hyperplasia

\section{DISCUSSION}

The finding of young age group of 47 years in bladder carcinoma patients in this study is comparable to 46years found in previous studies done in schistosomiasis endemic areas. ${ }^{4,5}$ The exposure to schistosomiasis occur in childhood and hence development of bladder carcinoma at young age. The Male: Female ratio of 12: 1 is comparable to the previous study done by Mungadi and Malami ${ }^{4}$ where the ratio was 11:1. All the patients in control group were males. The predominance of males is not surprising as they formed the main agricultural and fishing work force in this environment. ${ }^{4}$ most of our patients are farmers as reported in other schistosomal endemic areas. ${ }^{4,5}$

The commonest risk factor (85\%) of bladder carcinoma in the present study was schistosomiasis as observed by previous study in this area. ${ }^{5}$ The high sensitivity and specificity of Survivin of $100.0 \%$ is comparable to the 94.0-100.0\% observed by previous studies. ${ }^{16-17}$ Urine survivin had PPV and NPV of $100.0 \%$ and $80.2 \%$ respectively in this study, this is similar to the $100.0 \%$ and $86.0 \%$ respectively reported by a previous study. ${ }^{18}$

In the present study survivin cut off value of 18.81 $\mathrm{pg} / \mathrm{ml}$ was used, this was higher than $12 \mathrm{pg} / \mathrm{ml}$ value used by most of the studies, ${ }^{13-16}$ but comparable to 17.7 $\mathrm{pg} / \mathrm{ml}$ used by one of the studies. ${ }^{17}$ Urine cytology has lower sensitivity but similar specificity as compared to the urine survivin in the present as reported by a previous study. ${ }^{13,17}$ The sensitivity of urine survivin and urine cytology were $100.0 \%$ and $29.1 \%$ respectively, $\mathrm{p}=$ 0.05 . Using ROC curve the optimal cut off value of $18.81 \mathrm{pg} / \mathrm{ml}$ for survivin that yielded $100 \%$ sensitivity and specificity is comparable to $17.7 \mathrm{pg} / \mathrm{ml}$ suggested by Srivastava et $\mathrm{a}^{17}$, which gave sensitivity and specificity of $82.9 \%$ and $81.1 \%$ respectively.

The commonest histopathological type of bladder carcinoma in this study was SCC as reported by the previous study. ${ }^{4}$ The finding of schistosoma ova in biopsy tissues of the bladder carcinoma patients in this study was similar to what were reported by the previous studies. ${ }^{4,5}$

Patients with benign urological conditions and HVs were negative for survivin as observed by a previous study. ${ }^{14}$ But in contrary to the previous study, the patients with prostate cancer in current study yielded false positive results. ${ }^{19}$ The finding of high concentration of survivin in patients with bladder carcinoma compared with HVs and patients with benign urologic diseases is similar to what were observed by previous studies. ${ }^{5,17}$ There is correlation of mean survivin concentration with grade of bladder carcinoma as reported by the previous studies, $(\mathrm{p}=0.001) .{ }^{10,13}$

The concentration of the Survivin in this study correlated negatively with the stage of the bladder carcinoma which was contrary to what was observed by the previous studies. ${ }^{19,17}$ This may be explained by fewer number 
of patients with early disease (2) as compared to those with advanced disease (38). In the present study, there is significant correlation between the mean survivin concentration and histological sub-types. The mean survivin concentrations in the patients with adenocarcinoma and SCC were significantly higher than that of the patients with TCC $(\mathrm{p}=0.001)$.

\section{CONCLUSION}

Urinary survivin at a cut off value $18.8 \mathrm{pg} / \mathrm{ml}$ of is $100 \%$ sensitive, specific and predictive of bladder carcinoma in our environment, which is endemic for schistosomiasis. The marker correlated positively with the grade of bladder carcinoma and is associated with false positive results in patients with prostate cancer.

Acknowledgement: Prof. Aminu Mode, Department of modern European Language and Linguistics, Usmanu Danfodiyo University Sokoto, Nigeria for grammatical corrections.

\section{REFERENCES}

1. Parkin DM. The global burden of urinary bladder cancer. Scand J Urol Nephrol Suppl. 2008;5599 (218):12-20.

2. Sani AM, Umar HP, Bawa AA, Ismaila AM, Abubakar DA. A descriptive Retrospective study of pattern of malignant diseases in Sokoto North Western Nigeria (1999-2004). J Med Sci. 2007;7(6):1033-1038.

3. David PW. Bladder tumour. In: Wein AJ, Partin AW, Peters CA, editors. Campbell -Walsh Urology. 11th ed. Philadelphia; 2016:6298-6303.

4. Mungadi IA, Malami SA. Urinary bladder cancer and schistosomiasis in North-Western Nigeria. West Afr J Med. 2007;26(3):226-229.

5. Rambau PF, Chalya PL, Jackson K. Schistosomiasis and urinary bladder cancer in North Western Tanzania: a retrospective review of 185 patients. Infect Agent Cancer. 2013;8:19-25.

6. Kristen LG, Badrinath K. Urinary markers for bladder cancer. AUA update series. 26th ed. 2007.

7. David PW. Urothelial tumors of the bladder. In: Kavoussi LR, Novick AC, Partin AW, Peters CA, editors. Campbell-Walsh's Urology. 10th ed. Phila- delphia: Sunders Elsevier's incorporation; 2012:2303-2374.

8. Tilki D, Burger M, Dalbagni G, Grossman HB, Hakenberg OW, Palou J, et al. Urine markers for detection and surveillance of non-muscle-invasive bladder cancer. Eur Urol. 2011;60(3):484-492.

9. Ceballos-Cancino G, Espinosa M, Maldonado V, Melendez -Zajgl J. Regulation of mitochondrial Smac/DIABLO-selective release by survivin. Oncogene. 2007;26:7569-7575.

10. Margulis V, Lotan Y, Shariat SF, Margulis V, Lotan Y, Shariat SF. Survivin: a promising biomarker for detection and prognosis of bladder cancer. World J Urol. 2008;26(1):59-65.

11. World Medical Association. World Medical Association Declaration of Helsinki. Bull World Health Organisation. 2001;79(4):373-374.

12. Marluce B, William HK. Urinary tract. In: Comprehensive cytopathology. 3rd ed. Philadelphia: Sunders, Elsevier incorporation; 1997:409-423.

13. Sharaf S, Ketat A, Diab I, Dwidar F, Sameh W. Evaluation of tissue and urinary survivin expression in non-muscle-invasive bladder cancer. African $J$ Urol. 2012;18(4):143-148.

14. Aviwioro OG. Tissue processing. In: Histochemistry and tissue pathology; principles and techniques. 1st ed. Ibadan: Claverianum; 2000:79-106.

15. America IBL. Human Total Survivin Enzyme Immunometric Assay Kit. Product information. Minneapolis; 2008.

16. Moussa O, Abol-Enein H, Bissada NK, Keane T, Ghoneim MA, Watson DK. Evaluation of survivin reverse transcriptase-polymerase chain reaction for noninvasive detection of bladder cancer. $J$ Urol. 2006; 175:2312-2316.

17. Srivastava AK, Singh PK, Srivastava K, Dalela D, Rath SK, Goel MM, et al. Diagnostic Role of Survivin in Urinary Bladder Cancer. Asian Pacific $J$ Cancer Prev. 2013;14:81-85.

18. Wang H, Xi X, Kong X, Huang G, Ge G. The expression and significance of survivin mRNA in urinary bladder carcinomas. J Cancer Res Clin Oncol. 2004;130(8):487-90.

19. Smith SD, Wheeler MA, Plescia J. Urine detection of survivin and bladder cancer. JAMA. 2001;285:324-328. 